\title{
Screening Eucalyptus cloeziana and E. argophloia Populations for Resistance to Puccinia psidii
}

D. J. Lee, Forest Industries Research Centre, University of the Sunshine Coast, Maroochydore DC Qld 4558 Australia, and Forestry \& Biosciences, Agri-Science Queensland, Department of Agriculture, Fisheries and Forestry, Brisbane Qld 4001 Australia; J. T. Brawner, Forest Industries Research Centre, University of the Sunshine Coast and CSIRO Plant Industries, St. Lucia Qld 4067 Australia; and G. S. Pegg, Forest Industries Research Centre, University of the Sunshine Coast and Forestry \& Biosciences, Agri-Science Queensland, Department of Agriculture, Fisheries and Forestry

\begin{abstract}
Lee, D. J., Brawner, J. T., and Pegg, G. S. 2015. Screening Eucalyptus cloeziana and E. argophloia populations for resistance to Puccinia psidii. Plant Dis. 99:71-79.

Disease screening to determine the threat Puccinia psidii poses to plantation and native eucalypts in Australia was undertaken in half-sib families of two contrasting eucalypt species, Eucalyptus cloeziana and E. argophloia. Artificial inoculation with a single-lesion isolate of $P$. psidii was used to screen these species for resistance to the biotype of $P$. psidii established in Australia. The objective was to characterize resistance to $P$. psidii within these two distinct species: E. argophloia, a vulnerable species with a narrow distribution, and E. cloeziana, a species with a broad and extensive distribution in Queensland. Results

P. psidii infection than provenances from coastal regions. Heritability estimates for the two assessment systems used (resistance on a 1-to-5 ordinal scale verses resistance on a 0-to- 1 binomial scale) were low to high (0.24 to 0.63$)$ for E. argophloia and moderate to high (0.4 to 0.91$)$ for $E$. cloeziana, indicating a significant level of additive genetic variance for rust resistance within the populations. This study demonstrates the potential to select resistant families within the tested populations and indicates that $P$. psidii could detrimentally affect these species in native forests, nurseries, and plantations.
\end{abstract} for E. cloeziana indicate that inland provenances are more resistant to
Puccinia psidii is considered to be one of the biggest threats to myrtaceous genera and species around the world, with both natural and planted myrtaceous species and areas of origin of myrtaceous species being vulnerable to the disease (13). It is spreading rapidly and is now established across North and South America (18), Hawaii (37), Australia (12), and, more recently, South Africa (33).

Since P. psidii was first detected in Australia in April 2010 (12), it has spread along the east coast from temperate areas in Victoria to tropical regions of far northern Queensland. Based on observations of natural infection within Australia, the rust has been found on more than 200 species from 37 different genera $(11,32)$. It is expected that the impact on mature eucalypt trees of these species will be slight; however, impacts on regenerating seedlings may be severe enough to cause changes in native forest composition and to affect the development of plantation forests.

In a study to understand the risk the disease posed to Australia (38), wide variation in susceptibility to eucalyptus rust has been observed between and within commercially important eucalypt species (genera Eucalyptus and Corymbia) tested with the main rust biotypes in Brazil. Inter- and intraspecific variability was observed within the range of myrtaceous species tested. Of the eucalypt species tested, Eucalyptus cloeziana, E. regnans, and E. grandis were ranked as most susceptible to $P$. psidii of the eucalypts tested, while spotted gum species Corymbia citriodora subsp. citriodora and $C$. maculata had $>72 \%$ of seedlings rated as resistant (38). This confirmed earlier glasshouse and field-based assessments (14) that identified E. grandis and E. cloeziana as being highly susceptible species.

Alfenas et al. (1) highlighted the potential value of E. cloeziana for commercial plantation development in Brazil due to its high

Corresponding author: D. J. Lee, E-mail dlee@usc.edu.au

Accepted for publication 17 June 2014.

http://dx.doi.org/10.1094/PDIS-04-14-0353-RE

(C) 2015 The American Phytopathological Society resistance to the fungal canker disease Chrysoporthe cubensis and value as a tree species for solid wood production. However, its high susceptibility to the rust caused by $P$. psidii limits its use in areas where climatic conditions favor infection. Alfenas et al. (1), when attempting to develop rust-resistant E. cloeziana clones, tested 3,500 seedlings from various Brazilian seedlots; however, only $2 \%$ of the seedlings were identified as being both resistant to $P$. psidii and clonable. This is not surprising because the species is not considered amenable to commercial-scale vegetative propagation $(3,35)$ and the genetic base of E. cloeziana in Brazil is of unknown origin and diversity.

The impact of $P$. psidii on eucalypts in Australia, based on field observations alone, is thus far restricted to seedlings (e.g., Corymbia citriodora subsp. variegata, C. torelliana, E. cloeziana, and E. tereticornis; 32). However, on E. curtisii, the disease has been observed causing dieback of developing leaves, shoots, and meristems of mature trees and on the coppice regrowth of $E$. carnea (32). Preliminary host testing of the rust in Australia has also revealed a wide range of host species, some of significance to the plantation forest industry, including E. agglomerata, E. cloeziana, E. dunnii, E. globulus, E. grandis, E. pellita, E. pilularis, E. saligna, and $C$. citriodora $(11,28)$. Pegg et al. (31) characterized resistance to $P$. psidii within the Corymbia species complex (C. citriodora subsp. variegata, $C$. citriodora subsp. citriodora, $C$. henryi, and $C$. torelliana) used in existing breeding programs (25) of these spotted gum species to quantify inter- and intraspecific variability. They found that there was potential for $P$. psidii to detrimentally affect Corymbia in the nursery and in young plantations and also demonstrated the potential to select for resistance within the tested populations.

In this study, we examined the susceptibility of E. cloeziana and determined whether results from studies in Brazil were indicative of the susceptibility of the species when testing a wider range of provenances from across the native distribution of the species. In addition, we investigated the susceptibility of E. argophloia, an inland Eucalyptus sp. with a restricted natural range $30 \mathrm{~km}$ east to west and $20 \mathrm{~km}$ north to south in Queensland and limited genetic variability. E. argophloia is considered "vulnerable" (needing conservation, protection, and implementation of recovery plans to 
ensure that it remains a viable population) under the Queensland Nature Conservation Act 1992 (29), with approximately 1,000 trees remaining within the species native range (27). Both $E$. argophloia and E. cloeziana are important for hardwood plantation development in Queensland and are of increasing importance internationally for the production of high-value wood products or the development of plantations in areas previously considered marginal for plantation forestry. In addition, E. cloeziana from native forests is utilized for a wide range of wood products and is an ecologically significant species, being the only Eucalyptus sp. within the monotypic subgenus Idiogenes (34). Therefore, in this study, we compared the resistance levels of a widely distributed species, E. cloeziana, with a species with a limited distribution, E. argophloia, to the introduced pathogen $P$. psidii.

\section{Materials and Methods}

E. argophloia. Susceptibility of E. argophloia was examined by evaluating 120 open-pollinated families of the species from across its range (Fig. 1). Of these, 20 families were from wild trees from three subpopulations: Burncluith, 11 families; Fairyland, 4 families; and Burra Burri, 5 families (Table 1). The remaining 100 open-pollinated half-sib families were trees of known provenance and maternal pedigree from an ex situ conservation stand of the species located near Cecil Plains, Queensland (27).

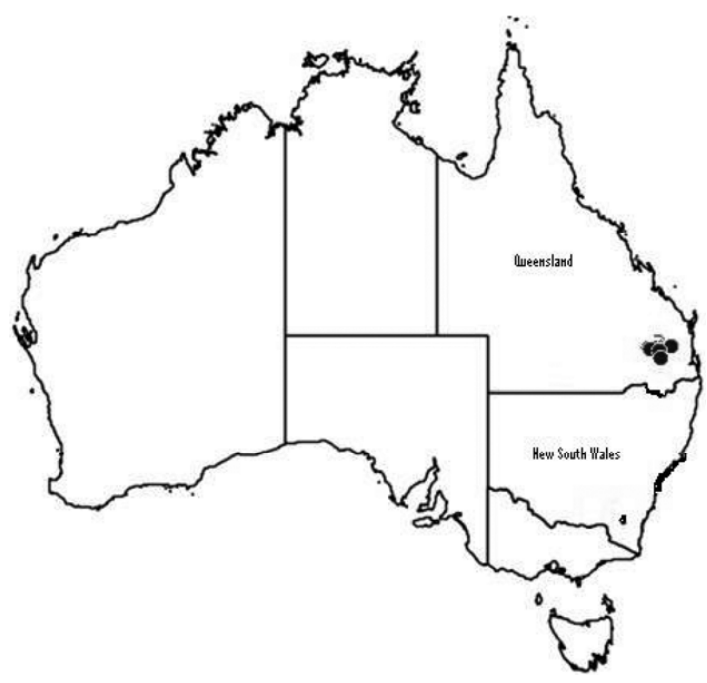

Fig. 1. Eucalyptus argophloia distribution; Atlas of living Australia (2). Each dot represents a herbarium record.
E. cloeziana. Differences in susceptibility were examined across the natural range of E. cloeziana (Fig. 2); provenances from the four ecotypes of the species identified by Turnbull (36) were examined for susceptibility after inoculation with P. psidii. In total, 120 half-sib families from 94 wild seedlots and 26 families sourced from a mixed-provenance seed orchard (Table 1) were examined for susceptibility to $P$. psidii.

Experimental design. The E. argophloia and E. cloeziana experimental materials were evaluated for susceptibility to $P$. psidii in discrete trials. Each trial was established as an incomplete block design with 120 treatments (open-pollinated half-sib families) randomized within 15 replicates, where a single tree from each family was represented in each replicate, as described in Pegg et al. (31).

Seedlings. Seeds were sown in the standard 40-cell Hyco V93 trays used to grow eucalypts for plantation forestry in Australia, in the glasshouse, during March 2012. Each cell in the tray had a 70$\mathrm{ml}$ plastic insert to facilitate sorting and trial design. The potting medium consisting of $50 \%$ pine bark fines ( 0 to $10 \mathrm{~mm}$ ), $25 \%$ pine bark peat, $25 \%$ coarse perlite, and a mix of 12- to 14-month slowrelease Osmocote (N-P-K, 17.9:0.8:7.3) at a rate of $4 \mathrm{~kg} / \mathrm{m}^{3}$, gypsum at $1 \mathrm{~kg} / \mathrm{m}^{3}$, Micromax at $1 \mathrm{~kg} / \mathrm{m}^{3}$, and granular wetting agent Hydroflo2 at $1 \mathrm{~kg} / \mathrm{m}^{3}$. Plants were irrigated five times a day for 3 min at each irrigation time using an overhead spray and fertilized with both Nitrosol $(10.5 \% \mathrm{~N}, 2.3 \% \mathrm{P}, 6.8 \% \mathrm{~K}$, and some trace elements; Yates Pty Ltd.) and Seasol (primarily trace elements; Seasol International Pty Ltd.) liquid fertilizer at $2 \mathrm{ml} / \mathrm{liter}$ every 2 weeks.

Inoculum. A single lesion isolate of $P$. psidii (BRIP number 57793) was collected from Rhodamnia sessiliflora growing in the Chapel Hill suburb of Brisbane, Queensland, Australia. Urediniospores from a single pustule were collected using a fine-bristled paint brush and washed into $5 \mathrm{ml}$ of sterile distilled water (SDW) to which one drop of the surfactant Tween 20 was added. This solution was then applied onto Syzygium jambos and $R$. rubescens seedlings to further propagate spores for screening.

These plants were then covered with black plastic bags, which were sealed to maintain a high humidity level, and placed into an incubator at 18 to $20^{\circ} \mathrm{C}$ for $24 \mathrm{~h}$. After $24 \mathrm{~h}$, plants were transferred to a shade-house and watered by hand as required. Urediniospore production was monitored and spores collected every 2 to 3 days until spore production ceased. These urediniospores were then inoculated back onto other $S$. jambos and $R$. rubescens seedlings, a process repeated until sufficient numbers of spores had been collected for inoculation. Urediniospores were then placed in a desiccator for 7 days before being placed into Nunc tubes and stored at $-80^{\circ} \mathrm{C}$ until required.

Table 1. Eucalyptus argophloia and E. cloeziana provenances and seedlots evaluated for Puccinia psidii resistance ${ }^{\mathrm{w}}$

\begin{tabular}{|c|c|c|c|c|c|}
\hline Species, population & Seed lots ${ }^{x}$ & Latitude & Longitude & Altitude $(m \text { ASL })^{y}$ & Mean annual rainfall $(\mathrm{mm})$ \\
\hline \multicolumn{6}{|l|}{ E. argophloia } \\
\hline Burncluith & $88(11 / 77)$ & -26.578 & 150.767 & 310 & 673 \\
\hline Burra-Burri & $17(5 / 12)$ & -26.512 & 151.019 & 313 & 673 \\
\hline Fairyland & $15(4 / 11)$ & -26.504 & 150.936 & 310 & 673 \\
\hline \multicolumn{6}{|l|}{ E. cloeziana } \\
\hline Allies Ck & 10 & -25.983 & 151.101 & 380 & 680 \\
\hline Home & 11 & -26.05 & 152.702 & 220 & 1,230 \\
\hline Koko & 11 & -25.933 & 150.867 & 299 & 681 \\
\hline Mt Mulligan & 9 & -16.901 & 144.85 & 700 & 825 \\
\hline Mt Pinnacle & 9 & -17.251 & 145.066 & 600 & 860 \\
\hline Mungy & 12 & -25.283 & 151.351 & 200 & 725 \\
\hline Seed orchard ${ }^{\mathrm{z}}$ & 26 & & & & \\
\hline Toolara & 10 & -26.217 & 152.883 & 80 & 1,690 \\
\hline Veteran & 7 & -26.117 & 152.667 & 100 & 1,130 \\
\hline Wolvi & 10 & -26.117 & 152.783 & 120 & 1,230 \\
\hline Woondum & 5 & -26.251 & 152.817 & 160 & 1,600 \\
\hline
\end{tabular}

\footnotetext{
${ }^{\mathrm{w}}$ Latitude and longitude are for the original sources of the population.

${ }^{\mathrm{x}}$ Data in parentheses indicate wild sourced seed/seed from trees in an ex situ conservation stand, if applicable.

y $\mathrm{ASL}=$ above sea level.

${ }^{\mathrm{z}}$ Pedigree information of this material is detailed in Table 7.
} 
Inoculation. Urediniospores were removed from $-80^{\circ} \mathrm{C}$ storage and allowed to warm to room temperature prior to being added to SDW. The surfactant Tween 20 was added at a rate of two drops per $100 \mathrm{ml}$ of SDW and the spore suspension was stirred to reduce clumping. Spore counts were then conducted using a hemocytometer and the suspension adjusted to a concentration of $1 \times 10^{5}$ spores/ml for use in the subsequent inoculation.

Seedlings were inoculated using a fine mist spray (2.9 $\mathrm{kPa}$ pressure), generated by a compressor-driven spray gun (Iwata Studio series 1/6 hp; Gravity spray gun RG3, Portland, OR), applied to the upper and lower leaf surfaces of the seedlings, ensuring that all leaves were coated with a fine mist but runoff of the spore suspension was avoided, as described by Pegg et al. (31). In all, $10 \mathrm{~S}$. jambos and $10 R$. rubescens seedlings were used as susceptible controls. These susceptible controls were placed randomly within replicates and were inoculated in the same manner as those of the test species.

Seedling trays were placed into solid plastic tubs and then onto a metal bench layered with a plastic sheet. Immediately after inoculation, seedlings were covered with a plastic sheet for $24 \mathrm{~h}$ to maintain high humidity levels and leaf wetness in a controlled environment room set between 18 and $20^{\circ} \mathrm{C}$ in the dark. Hot tap water $\left(60^{\circ} \mathrm{C}\right)$ was applied to the lower plastic sheet immediately after inoculation to ensure that high humidity levels were achieved rapidly. After $24 \mathrm{~h}$, plastic sheeting was removed and plants were grown in a shadehouse and hand watered as required. Disease symptom progression was monitored daily.

Disease assessments and rating system. Seedlings were monitored for symptom development and assessed 12 to 14 days after inoculation for disease severity on new shoots and expanding leaves using a 1-to-5 disease rating scale according to Junghans et al. (31), where $1=$ no symptoms evident or no presence of yellow flecking; 2 = presence of a hypersensitive reaction (HR), with fleck or necrosis; $3=$ small pustules, $<0.8 \mathrm{~mm}$ in diameter, with 1 or 2 uredinia; 4 = medium-sized pustules, 0.8 to $<1.6 \mathrm{~mm}$ in diameter, with about 12 uredinia; and $5=$ large pustules, $>1.6 \mathrm{~mm}$ in diameter, with 20 or more uredinia on leaves, petioles, or shoots. A binomial scale ( 0 and 1$)$ was also evaluated by converting the disease rating scale, with scores of 1 and 2 considered to indicate resistance because no pustules were formed (given a score of 0 ) and the classes 3 to 5 given a score of 1 . The binomial scale infers resistance and susceptibility rather than degree of damage caused by rust that is inferred by the ordinal scale. Seedlings without new flush were not rated against either scale and, therefore, were included in the analysis as missing values. Repeat inoculations were conducted on seedlings rated as 1 on the 1-to-5 disease rating scale to ensure that they were not escapes.

Statistical analyses. Two sets of analyses were used to examine the data collected from the assessment of inoculated seedlings. Initially, a broad examination of each species was undertaken, with comparisons made among populations within species and families within provenances of the species. These analyses were primarily undertaken to indicate the significance difference between population means so that comparisons could be made among experimental units and relationships with environmental variables at the ecotype, provenance, and family level. A $\chi^{2}$ analysis was used to compare the nonparametric disease ratings and seedling resistance frequencies between provenances within species as well as families within provenances.

Secondly, genetic parameters were estimated for each species to provide an indication of the heritability of disease resistance and the importance of population effects on genetic parameter estimates. Genetic parameters were estimated on both the 1-to-5 disease rating scale and the binomial scale indicating resistance or susceptibility. Additionally, the relative importance of within and among population variation for rust resistance was examined by comparing narrow-sense heritability estimates $\left(h^{2}\right)$ derived from statistical models that included or excluded broad (e.g., ecotype) and narrow (e.g., provenance) population of origin effects. These two population effects were used to account for structure in the population that would bias estimates of additive variance and heritability upward.

Genetic parameters of rust resistance. Genetic analyses were undertaken to describe patterns of variation in disease resistance within and among various populations of each species, with variance components estimated from the half-sib families to provide estimates of genetic parameters. Factors allocating families to broad and narrow population structures were modeled to investigate their effects on $h^{2}$, where not accounting for population structure was assumed to lead to upward biases in the estimate of additive genetic variance (15).

Genetic parameters were approximated using estimates of the causal components of variance from a mixed model fit using the $\mathrm{R}$ package MCMCglmm $(20,21)$. Noninformative priors $(n=$ 0.002 ) were assumed for the variance component estimates and 100,000 Markov chain Monte Carlo (MCMC) iterations were completed for each generalized linear mixed model (glmm) analysis, with the initial 10,000 iterations discarded and every 100th iteration sampled. Four analyses were undertaken for each species, with the inclusion of broad and narrow population structures used to account for the effect of population structure. The simplest model, which did not account for any population structure, included random replication and open-pollinated family effects. The tray within replication or incomplete block effects was not significant $(P>0.05)$ for either species and, therefore, was dropped to obtain a more parsimonious model. Additional models included a fixed effect to account for the broad population classification and a random effect to account for the narrow population classification. In the case of E. cloeziana, the broad population effect equated to what has been called an ecotype (36) and the narrow population effect is what has typically been termed a provenance effect. In the case of E. argophloia, which has a small distribution range, the broad population classification was allocated to the provenance effect and the narrow population classification may be thought of as a locality effect, referring to groupings of families within each provenance. In both cases, the narrow population effect was nested within the broad population effect. The various formulations of these models were used to investigate the relative importance of additive genetic effects relative to two levels of population structure so that inferences could be made about the importance of screening among or within populations.

Narrow-sense $h^{2}$ were approximated using the following formulae, which is the ratio of additive genetic variance to the withinpopulation phenotypic variance,

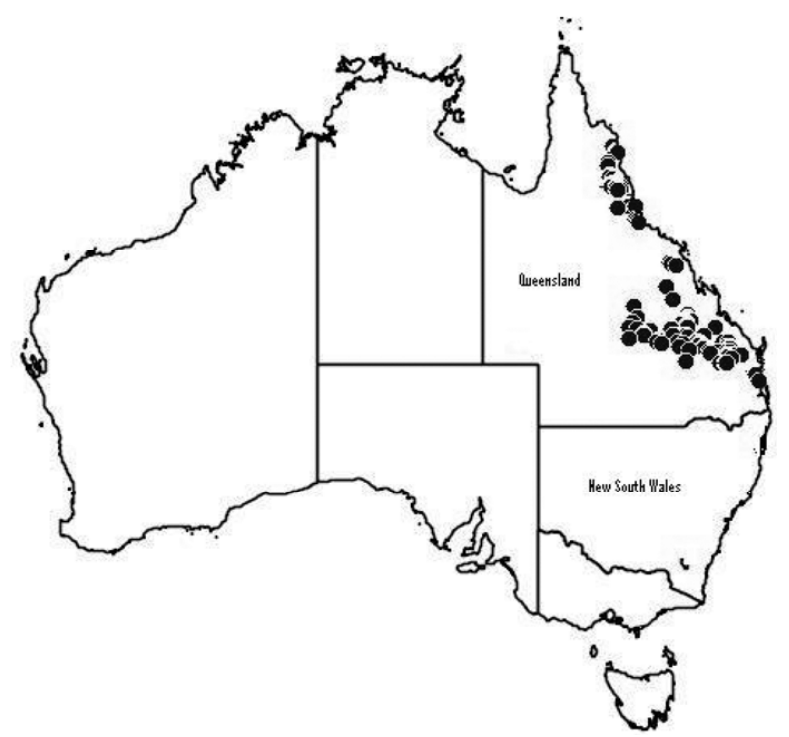

Fig. 2. Eucalyptus cloeziana distribution; Atlas of living Australia (2). Each dot represents a herbarium record. 


$$
\hat{h}_{i}^{2}=\frac{\hat{V}_{A_{i}}}{\hat{V}_{P_{i}}} \approx \frac{3 \hat{\sigma}_{\text {Family }_{i}}^{2}}{\hat{\sigma}_{\text {Family }_{i}}^{2}+\hat{\sigma}_{\text {Block }_{i}}^{2}+\hat{\sigma}_{\text {Error }_{i}}^{2}}
$$

This $h^{2}$ assumed that the coefficient of relationship was one-third (9), to account for the mixed mating system of eucalypts (19), rather than one-quarter, as is appropriate when families are composed of true half-sibs. For these generalized linear models, the error variance was fixed at one and the variance of the logit link function $(\pi \times \pi / 3)$ was added to the denominator $(8,16)$. In order to compare the among-population variance and among-family variances, effects for broad and narrow populations were included separately and together in the model to evaluate the changes in $h^{2}$ that may arise due to population structure.

\section{Results}

Symptom development. Symptoms (red-brown or chlorotic leaf spots) were first observed 4 and 5 days after inoculation on $E$. argophloia and E. cloeziana, respectively. Symptoms on E. argophloia appeared faster than those presenting on the $S$. jambos and $R$. rubescens seedlings used as susceptible controls, both of which showed evidence of chlorotic flecks 5 days after inoculation and severe infection (rating 5) at the time of assessment. Uredinia were initially observed after 7 days for E. argophloia and 8 days on E. cloeziana (Fig. 3).
Resistant and susceptible seedlings were identified within both species, across ecotypes (E. cloeziana) and provenances of these species. However, some families of E. cloeziana were found to be completely resistant to the disease even following reinoculation, to confirm that they were not escapes. A $\chi^{2}$ analysis was used to compare nonparametric disease rating data and seedling resistance frequencies between provenances within species and families within provenances.

Resistance of species. E. argophloia was more susceptible to rust infection by $P$. psidii, with only $46 \%$ of seedlings rated as being resistant and a mean disease rating of 3.5 compared with $68 \%$ of E. cloeziana seedlings and a mean rating of 2.8 .

Resistance within $\boldsymbol{E}$. argophloia. Resistance was significantly higher for seedlings originating from Fairyland and Burra-Burri than seedlings from the Burncluith provenance (Table 2). Fairyland had the most resistant seedlings but was not significantly different from Burra-Burri. For seedlings derived from the open-pollinated conservation stand, there were no significant differences among materials of known parentage. However, disease resistance levels were lower in the ex situ conservation stand material than seedlings collected in situ (Tables 2 and 3).

Resistance within $\boldsymbol{E}$. cloeziana provenances. All provenances of E. cloeziana studied, based on means of families, showed symptoms of infection by $P$. psidii (Table 4). Of the 10 provenances

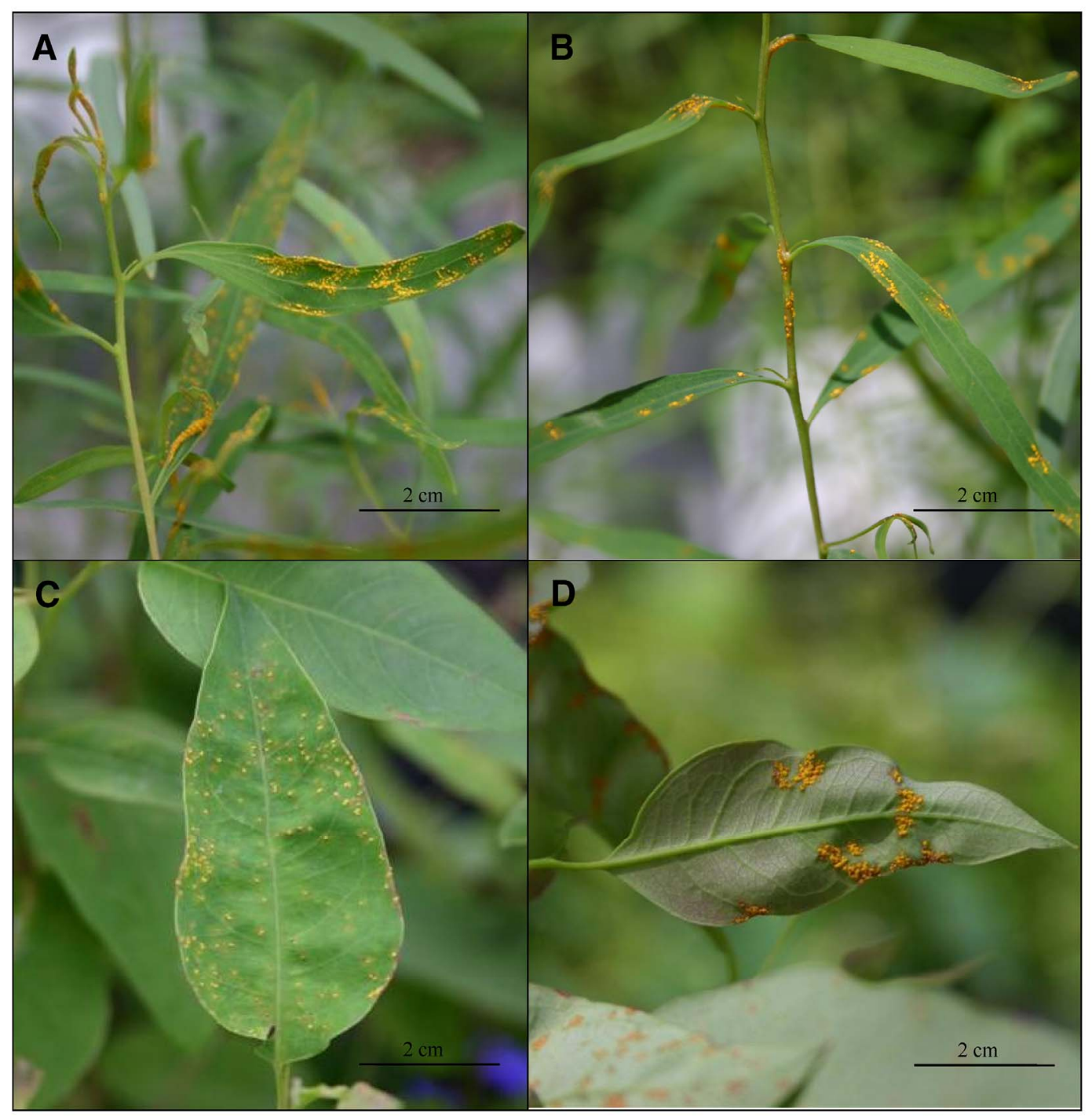

Fig. 3. Symptoms of Puccinia psidii infection after 14 days produced during the inoculation experiment with Eucalyptus argophloia and E. cloeziana. Seedlings were assessed using the five severity classes developed by Junghans et al. (23): A, E. argophloia with severe (class 5) rust infection with pustules on the leaves; B, E. argophloia with severe rust infection with pustules on the leaves and stem (class 5); C, E. cloeziana with moderate rust infection with small pustules on the leave (class 3 ); and D, E. cloeziana showing severe infection with large pustules forming on the abaxial surface of the leaves (class 5 ). 
sourced from wild seed, Koko (87\%) had the highest percentage of resistant seedlings, followed by Mt. Mulligan (86\%), Mt. Pinnacle (86\%), and Allies $\mathrm{Ck}(84 \%)$. The five most resistant provenances were inland ecotypes of the species. The five provenances from the south Queensland coastal ecotype had lower percentages of seedlings with resistance than the inland ecotypes (Table 4).

Resistance of families within $E$. cloeziana provenances. Resistance to $P$. psidii varied among and within families in all E. cloeziana provenances (Table 5). No family showed total susceptibility to the disease. However, families within Allies Creek, Koko, Mt. Mulligan, Mt. Pinnacle, Mungy, and Toolara showed much higher levels of resistance to $P$. psidii. Also, for each provenance, there were significant differences between the most resistant family and the most susceptible family when comparing the percentage of resistant seedlings; the exception was the Mt. Pinnacle population, in which all families had statistically similar resistance ratings (Table 5).

Resistance within seed orchard E. cloeziana. The 26 E. cloeziana half-sib families sourced from seed orchard trees have a range of resistant seedlings, 23 to $89 \%$ (Table 6), similar to that of the 94 half-sib families sourced from wild trees (21 to 100\%) (Table 5).

Heritability of resistance to $\boldsymbol{P}$. psidii. The causal component of variance associated with seedlot or maternal parent was used to produce estimates of heritability and approximate the percentage of

Table 2. Results from rust screening of Eucalyptus argophloia populations sourced from native range

\begin{tabular}{|c|c|c|c|}
\hline Population & $\begin{array}{c}\text { Mean disease } \\
\text { rating }\end{array}$ & $\begin{array}{c}\text { Number of } \\
\text { plants/severity class } \\
(1: 2: 3: 4: 5)^{y}\end{array}$ & $\begin{array}{c}\text { Resistant } \\
\text { seedlings } \\
(\%)^{\mathrm{z}}\end{array}$ \\
\hline Fairyland & $3.09 \pm 0.2$ & $3: 10: 20: 8: 8$ & $67 \mathrm{a}$ \\
\hline Burra-Burri & $3.03 \pm 0.2$ & 9:15:9:11:12 & $59 \mathrm{a}$ \\
\hline Burncluith & $3.76 \pm 0.1$ & $6: 11: 28: 56: 35$ & $33 \mathrm{~b}$ \\
\hline
\end{tabular}

${ }^{y}$ Severity classes based on Junghans et al. (23), with ratings 1 to 3 being considered to be resistant.

${ }^{\mathrm{z}}$ Resistant seedling percentage followed by the same letters shows means that do not differ significantly (pairwise comparison $P<0.05$ ).

Table 3. Results from rust screening of Eucalyptus argophloia populations sourced from an ex situ conservation stand

\begin{tabular}{lccc}
\hline Population & $\begin{array}{c}\text { Mean disease } \\
\text { rating }\end{array}$ & $\begin{array}{c}\text { Number of } \\
\text { plants/severity class } \\
(\mathbf{1 : 2 : 3 : 4 : 5 )}\end{array}$ & $\begin{array}{c}\text { Resistant } \\
\text { seedlings } \\
(\%)^{\mathbf{z}}\end{array}$ \\
\hline Fairyland & $3.5 \pm 0.1$ & $10: 21: 45: 45: 39$ & $47 \mathrm{a}$ \\
Burncluith & $3.4 \pm 0.04$ & $63: 149: 228: 339: 184$ & $46 \mathrm{a}$ \\
Burra-Burri & $3.6 \pm 0.1$ & $8: 12: 25: 38: 25$ & $42 \mathrm{a}$ \\
\hline
\end{tabular}

${ }^{y}$ Severity classes based on Junghans et al. (23), with ratings 1 to 3 being considered to be resistant.

${ }^{\mathrm{z}}$ Resistant seedling percentage followed by the same letters shows means that do not differ significantly (pairwise comparison $P<0.05$ ). variance attributable to additive genetic variance (Table 7). The $h^{2}$ for the five-point disease rating scale indicate that there is significant genetic variation in both species that may be used for the selection of rust-resistant populations. The level of genetic variance was consistently higher in E. cloeziana relative to E. argophloia regardless of the level of population structure assumed to be present. The E. cloeziana $h^{2}$ were 1 to $71 \%$ larger than estimates from similar models in E. argophloia.

When comparing the binomial (0 or 1$)$ rating (indicating the absence or presence of pustules) to the damage rating on a 1-to-5 scale, a consistent trend was also noted. This trend indicated that $h^{2}$ for the binomial trait were 2.4 to 3.0 times greater when averaged across the four population structures for E. cloeziana and E. argophloia, respectively.

Various classifications of the population structure within each species were used to evaluate the relative importance of genetic variance coming from broad and narrow population classifications. In $E$. cloeziana, this population structure included ecotype, provenances within ecotypes, and families within provenance; whereas, for E. argophloia, this population structure associated with provenance, locality, and family within provenance, based on the restricted distribution of the species. Depending on the assumption used for population structure, upward biases in $h^{2}$ caused by ignoring population structure were evident in all cases, with just one exception noted where the $h^{2}$ for E. argophloia increased when a genetic group effect was added to the model $(0.63$ versus 0.72$)$. It is unclear why this specific population classification differed from the trend because inclusion of both broad and narrow population classifications returned to the decreasing trend. To investigate this further, additional MCMC analyses were run with informative priors and alternative hyperparameters; all analyses returned similar results. As a further check, a deterministic ASReml (17) approach was used to generate estimates of variance assuming an underlying Gaussian distribution; this returned an $h^{2}(0.39 \pm 0.09)$ intermediate to the broad $(0.44 \pm 0.09)$ and broad plus narrow $(0.37 \pm 0.09)$ classifications, as expected.

\section{Discussion}

This is the first study to characterize rust resistance within $E$. $a r$ gophloia and the first study examining the susceptibility of a wide range E. cloeziana provenances and families from different ecotypes against what appears to be a single biotype of $P$. psidii (12) in Australia. Inter- and intraspecific variability was observed for both species, with results indicating that there is significant variation in resistance and potential to select families with reduced levels of infection. For E. cloeziana, there is also an indication that selection at the provenance or ecotype level is possible, with inland provenances showing significantly higher levels of resistance. However, our results also show the potential for an impact of $P$. psidii in nurseries and recently planted forests when using planting stock that has not been screened for resistance to $P$. psidii, particularly in the case of E. argophloia. The results would also suggest that, if the climatic conditions were suitable, $P$. psidii could affect native

Table 4. Comparisons of Eucalyptus cloeziana provenances screening for rust resistance

\begin{tabular}{llccc}
\hline Population or ecotype $^{\mathbf{x}}$ & Provenance & Mean disease rating & Number of plants/severity class (1:2:3:4:5) $^{\mathbf{y}}$ & ${\text { Resistant seedlings }(\%)^{\mathbf{z}}}^{\text {SQ Inland }}$ \\
NQ Inland & Koko & $2.2 \pm 0.1$ & $44: 26: 38: 11: 5$ & $87 \mathrm{a}$ \\
NQ Inland & Mt Mulligan & $2.2 \pm 0.1$ & $30: 20: 26: 11: 1$ & $86 \mathrm{a}$ \\
SQ Inland & Mt Pinnacle & $2.4 \pm 0.1$ & $25: 12: 39: 12: 0$ & $86 \mathrm{a}$ \\
SQ Inland & Allies Ck & $2.5 \pm 0.1$ & $28: 25: 50: 19: 1$ & $84 \mathrm{ab}$ \\
SQ Coastal & Mungy & $2.7 \pm 0.1$ & $32: 33: 62: 32: 9$ & $70 \mathrm{bc}$ \\
SQ Coastal & Home & $2.8 \pm 0.1$ & $43: 18: 46: 32: 24$ & $66 \mathrm{~cd}$ \\
SQ Coastal & Woondum & $2.9 \pm 0.1$ & $18: 6: 24: 18: 7$ & $65 \mathrm{~cd}$ \\
SQ Coastal & Toolara & $3.0 \pm 0.1$ & $24: 19: 48: 37: 14$ & $64 \mathrm{~d}$ \\
SQ Coastal & Veteran & $3.0 \pm 0.1$ & $19: 6: 40: 31: 7$ & $63 \mathrm{~d}$ \\
\hline
\end{tabular}

${ }^{\mathrm{x}}$ Based on the four ecotypes identified by Turnbull (36), with coastal and inland ecotypes identified in both north Queensland (NQ) and South Queensland (SQ).

y Severity classes based on Junghans et al. (23), with ratings 1 to 3 being considered to be resistant.

${ }^{\mathrm{z}}$ Resistant seedling percentage followed by the same letters shows means that do not differ significantly (pairwise comparison $P<0.05$ ). 
stands of E. argophloia, which exist west of the Great Dividing Range, an area not generally considered suitable for disease development based on disease forecasting models $(6,7)$. Nevertheless, the high-humidity frost hollow microclimate where E. argophloia is typically established as a plantation species is considered to be highly conducive to rust development.

When comparing species, the more widely distributed species, E. cloeziana (5), had higher levels of resistance and lower mean disease ratings in comparison with E. argophloia, an inland species with a restricted natural range. This could be attributed to the latter species evolving in dry areas that are less suitable to humiditysensitive fungi such as $P$. psidii. Maintaining resistance mechanisms in environments where fungi are less of a threat wouldn't be

Table 5. Comparisons of rust resistance of families within Eucalyptus cloeziana provenances from the species' native range

\begin{tabular}{|c|c|c|c|}
\hline $\begin{array}{l}\text { Provenance, } \\
\text { family }\end{array}$ & MDR $^{x}$ & $\begin{array}{l}\text { Plants/class } \\
(1: 2: 3: 4: 5)^{\mathrm{y}}\end{array}$ & $\begin{array}{l}\text { Resistant seed- } \\
\text { lings }(\%)^{z}\end{array}$ \\
\hline \multicolumn{4}{|l|}{ Allies Ck } \\
\hline $10820-117$ & $2.8 \pm 0.1$ & $1: 1: 12: 0: 0$ & $100 \mathrm{a}$ \\
\hline $10820-107$ & $2.4 \pm 0.3$ & $2: 4: 5: 1: 0$ & $92 \mathrm{a}$ \\
\hline $10820-115$ & $2.2 \pm 0.3$ & $2: 4: 4: 1: 0$ & $91 \mathrm{a}$ \\
\hline $10820-111$ & $2 \pm 0.4$ & $5: 1: 3: 1: 0$ & $90 \mathrm{a}$ \\
\hline $10820-124$ & $2.6 \pm 0.2$ & $1: 6: 6: 2: 0$ & $87 \mathrm{a}$ \\
\hline $10820-123$ & $2.6 \pm 0.3$ & $3: 1: 7: 2: 0$ & $85 \mathrm{a}$ \\
\hline $10820-119$ & $2.3 \pm 0.3$ & $3: 4: 2: 2: 0$ & $82 \mathrm{ab}$ \\
\hline $10820-118$ & $2.6 \pm 0.3$ & $3: 2: 6: 3: 0$ & $79 \mathrm{ab}$ \\
\hline $10820-120$ & $2.4 \pm 0.4$ & $5: 2: 4: 2: 1$ & $79 \mathrm{ab}$ \\
\hline $10820-125$ & $3 \pm 0.4$ & $2: 1: 1: 5: 0$ & $44 \mathrm{~b}$ \\
\hline \multicolumn{4}{|l|}{ Home } \\
\hline $\mathrm{k} 5660$ & $1.7 \pm 0.3$ & 10:2:1:1:1 & $87 \mathrm{a}$ \\
\hline k5664 & $2.5 \pm 0.3$ & $3: 3: 6: 2: 0$ & $86 \mathrm{ab}$ \\
\hline k5661 & $2 \pm 0.4$ & $10: 0: 2: 1: 2$ & $80 a b c$ \\
\hline $\mathrm{k} 5670$ & $2.4 \pm 0.3$ & $4: 6: 2: 1: 2$ & $80 a b c$ \\
\hline k5671 & $2.3 \pm 0.4$ & $6: 4: 2: 1: 2$ & $80 a b c$ \\
\hline k5667 & $2.8 \pm 0.3$ & $4: 1: 5: 4: 1$ & $67 \mathrm{abcd}$ \\
\hline $\mathrm{k} 5665$ & $3.2 \pm 0.3$ & $2: 1: 6: 4: 2$ & $60 \mathrm{abcd}$ \\
\hline k5659 & $3.4 \pm 0.3$ & $2: 0: 6: 4: 3$ & $53 \mathrm{bcd}$ \\
\hline k5666 & $3.4 \pm 0.3$ & $2: 0: 5: 6: 2$ & $47 \mathrm{~cd}$ \\
\hline k5658 & $3.8 \pm 0.3$ & $0: 1: 5: 4: 4$ & $43 \mathrm{~d}$ \\
\hline k5663 & $3.9 \pm 0.2$ & $0: 0: 6: 4: 5$ & $40 \mathrm{~d}$ \\
\hline \multicolumn{4}{|l|}{ Koko } \\
\hline $10819-126$ & $1.8 \pm 0.2$ & $6: 3: 4: 0: 0$ & $100 \mathrm{a}$ \\
\hline $10819-127$ & $2.5 \pm 0.2$ & 1:4:7:0:0 & $100 \mathrm{a}$ \\
\hline $10819-135$ & $1.4 \pm 0.3$ & $6: 1: 1: 0: 0$ & $100 \mathrm{a}$ \\
\hline $10819-138$ & $1.6 \pm 0.2$ & $8: 4: 1: 1: 0$ & $93 \mathrm{a}$ \\
\hline $10819-130$ & $2.2 \pm 0.3$ & $5: 1: 6: 1: 0$ & $92 \mathrm{a}$ \\
\hline $10819-134$ & $2.2 \pm 0.3$ & $4: 3: 4: 1: 0$ & $92 \mathrm{a}$ \\
\hline $10819-142$ & $2.1 \pm 0.4$ & $4: 0: 3: 1: 0$ & $87 \mathrm{ab}$ \\
\hline $10819-136$ & $1.9 \pm 0.4$ & $5: 3: 0: 2: 0$ & $80 \mathrm{ab}$ \\
\hline $10819-140$ & $3 \pm 0.3$ & $2: 0: 7: 2: 1$ & $75 \mathrm{ab}$ \\
\hline $10819-141$ & $3.1 \pm 0.4$ & $2: 2: 5: 0: 4$ & $69 \mathrm{~b}$ \\
\hline $10819-129$ & $2.6 \pm 0.4$ & $1: 5: 0: 3: 0$ & $67 \mathrm{~b}$ \\
\hline \multicolumn{4}{|l|}{ Mt Mulligan } \\
\hline $10104-5$ & $2 \pm 0.2$ & 3:5:3:0:0 & $100 \mathrm{a}$ \\
\hline $10104-7$ & $1.5 \pm 0.2$ & $6: 4: 1: 0: 0$ & $100 \mathrm{a}$ \\
\hline $10104-8$ & $1.1 \pm 0.1$ & 10:1:0:0:0 & $100 \mathrm{a}$ \\
\hline $10104-9$ & $1.6 \pm 0.2$ & 7:3:2:0:0 & $100 \mathrm{a}$ \\
\hline $10104-10$ & $2 \pm 0.5$ & $2: 1: 2: 0: 0$ & $100 \mathrm{a}$ \\
\hline $10104-3$ & $3 \pm 0.2$ & $0: 3: 6: 3: 0$ & $75 a$ \\
\hline $10104-4$ & $3.4 \pm 0.3$ & $0: 0: 5: 1: 1$ & $71 \mathrm{ab}$ \\
\hline 10104-1 & $3 \pm 0.3$ & $1: 1: 5: 3: 0$ & $70 a b$ \\
\hline $10104-2$ & $3 \pm 0.4$ & $1: 2: 2: 4: 0$ & $55 \mathrm{~b}$ \\
\hline \multicolumn{4}{|l|}{ Mt Pinnacle } \\
\hline $10105-3$ & $2.5 \pm 0.3$ & 2:0:6:0:0 & $100 \mathrm{a}$ \\
\hline $10105-4$ & $1 \pm 0$ & $5: 0: 0: 0: 0$ & $100 \mathrm{a}$ \\
\hline \multirow[t]{2}{*}{$10105-5$} & $1.8 \pm 0.4$ & $3: 1: 2: 0: 0$ & $100 \mathrm{a}$ \\
\hline & & \multicolumn{2}{|c|}{ (continued on next column) } \\
\hline
\end{tabular}

${ }^{\mathrm{x}} \mathrm{MDR}=$ mean disease rating.

${ }^{y}$ Number of plants per severity class. Severity classes based on Junghans et al. (23), with ratings 1 to 3 being considered to be resistant.

${ }^{\mathrm{z}}$ Resistant seedling percentage within each provenance followed by the same letters shows means that do not differ significantly (pairwise comparison $P<0.05)$. an evolutionary advantage; therefore, an association with rainfall or humidity may be hypothesized. However, examination of the $E$. cloeziana populations or ecotypes does not support this reasoning, with the populations from coastal areas demonstrating higher average rust scores. In addition, there was no discernible relationship between resistance and climate at the origin within the Corymbia populations screened for resistance (31). Based on these diverse species, support could not be found for the idea that evolution and maintenance of fungal resistance mechanisms were linked to growth in humid areas in the eucalypts.

The relatively high susceptibility levels of E. argophloia seen in this study would suggest that $P$. psidii may pose a significant threat to this vulnerable species. However, detections of the disease have not been made beyond the Great Dividing Range, apart from isolated detections in nurseries (32). It does, however, demonstrate the potential for impact in these areas if conditions became more con-

Table 5. (continued from preceding column)

\begin{tabular}{|c|c|c|c|}
\hline $\begin{array}{l}\text { Provenance, } \\
\text { family }\end{array}$ & MDR $^{x}$ & $\begin{array}{l}\text { Plants/class } \\
(1: 2: 3: 4: 5)^{y}\end{array}$ & $\begin{array}{l}\text { Resistant seed- } \\
\quad \text { lings }(\%)^{\mathrm{z}}\end{array}$ \\
\hline $10105-7$ & $2.6 \pm 0.3$ & 1:1:5:0:0 & $100 \mathrm{a}$ \\
\hline $10105-11$ & $2.5 \pm 0.2$ & $2: 4: 6: 1: 0$ & $92 \mathrm{a}$ \\
\hline $10105-2$ & $2 \pm 0.4$ & $4: 2: 2: 1: 0$ & $89 a$ \\
\hline $10105-8$ & $2.6 \pm 0.3$ & $4: 0: 7: 3: 0$ & $79 a$ \\
\hline $10105-6$ & $2.8 \pm 0.2$ & $1: 3: 6: 3: 0$ & $77 \mathrm{a}$ \\
\hline $10105-10$ & $2.8 \pm 0.3$ & $3: 1: 5: 4: 0$ & $69 \mathrm{a}$ \\
\hline \multicolumn{4}{|l|}{ Mungy } \\
\hline $10823-195$ & $1.7 \pm 0.2$ & $8: 4: 3: 0: 0$ & $100 \mathrm{a}$ \\
\hline $10823-196$ & $2.3 \pm 0.2$ & $3: 6: 4: 2: 0$ & $87 \mathrm{a}$ \\
\hline $10823-190$ & $2.1 \pm 0.3$ & 7:0:5:2:0 & $86 \mathrm{a}$ \\
\hline $10823-187$ & $2.6 \pm 0.4$ & $3: 2: 5: 1: 1$ & $83 a$ \\
\hline $10823-188$ & $2.3 \pm 0.3$ & $4: 5: 2: 3: 0$ & $79 \mathrm{a}$ \\
\hline $10823-194$ & $2.7 \pm 0.3$ & $2: 3: 5: 3: 0$ & $77 \mathrm{a}$ \\
\hline $10823-197$ & $3.1 \pm 0.3$ & $1: 2: 8: 2: 2$ & $73 \mathrm{a}$ \\
\hline $10823-182$ & $3.2 \pm 0.1$ & $0: 1: 9: 4: 0$ & $71 \mathrm{a}$ \\
\hline $10823-199$ & $2.8 \pm 0.3$ & $3: 2: 6: 3: 1$ & $69 a$ \\
\hline $10823-180$ & $3.1 \pm 0.3$ & $1: 3: 5: 5: 1$ & $60 \mathrm{~b}$ \\
\hline $10823-192$ & $3.3 \pm 0.3$ & $0: 3: 4: 3: 2$ & $58 \mathrm{~b}$ \\
\hline $10823-184$ & $3.4 \pm 0.2$ & $0: 2: 6: 4: 2$ & $57 \mathrm{~b}$ \\
\hline \multicolumn{4}{|l|}{ Toolara } \\
\hline $\mathrm{k} 5650$ & $1.8 \pm 0.2$ & $5: 8: 2: 0: 0$ & $100 \mathrm{a}$ \\
\hline k5651 & $2.4 \pm 0.2$ & $3: 4: 7: 1: 0$ & $93 \mathrm{ab}$ \\
\hline K5649 & $2.1 \pm 0.4$ & $8: 1: 2: 1: 2$ & $86 \mathrm{ab}$ \\
\hline k5652 & $3 \pm 0.2$ & 0:2:9:2:0 & $85 \mathrm{ab}$ \\
\hline k5648 & $3.2 \pm 0.2$ & $0: 1: 10: 2: 1$ & $73 a b$ \\
\hline k5655 & $2.9 \pm 0.4$ & $3: 0: 4: 5: 0$ & $58 \mathrm{~b}$ \\
\hline $\mathrm{k} 5656$ & $3.5 \pm 0.2$ & $0: 1: 6: 7: 1$ & $47 \mathrm{c}$ \\
\hline k5657 & $3.4 \pm 0.3$ & $2: 1: 4: 5: 3$ & $47 \mathrm{c}$ \\
\hline $\mathrm{k} 5653$ & $3.5 \pm 0.4$ & $3: 1: 1: 6: 4$ & $33 \mathrm{~d}$ \\
\hline k5654 & $4 \pm 0.2$ & $0: 0: 3: 8: 3$ & $21 \mathrm{e}$ \\
\hline \multicolumn{4}{|l|}{ Veteran } \\
\hline k5677 & $2.4 \pm 0.3$ & $4: 2: 7: 1: 0$ & $93 \mathrm{a}$ \\
\hline k5679 & $2.9 \pm 0.2$ & $2: 1: 9: 3: 0$ & $80 \mathrm{a}$ \\
\hline k5676 & $2.9 \pm 0.3$ & $3: 1: 6: 4: 1$ & $67 \mathrm{a}$ \\
\hline k5680 & $2.5 \pm 0.3$ & $6: 0: 4: 5: 0$ & $67 \mathrm{a}$ \\
\hline $\mathrm{k} 5674$ & $3.1 \pm 0.3$ & $2: 0: 7: 5: 0$ & $40 \mathrm{ab}$ \\
\hline k5675 & $3.5 \pm 0.3$ & $2: 1: 3: 6: 3$ & $40 \mathrm{ab}$ \\
\hline $\mathrm{k} 5678$ & $3.8 \pm 0.2$ & $0: 1: 4: 7: 3$ & $33 \mathrm{~b}$ \\
\hline \multicolumn{4}{|l|}{ Wolvi } \\
\hline k5637 & $2.4 \pm 0.3$ & $4: 3: 4: 1: 1$ & $85 \mathrm{a}$ \\
\hline $\mathrm{k} 5642$ & $2.7 \pm 0.2$ & $2: 3: 7: 3: 0$ & $80 \mathrm{a}$ \\
\hline $\mathrm{k} 5645$ & $3 \pm 0.3$ & $2: 2: 7: 2: 2$ & $79 \mathrm{ab}$ \\
\hline k5647 & $2.9 \pm 0.3$ & 4:0:6:4:1 & $67 a b c$ \\
\hline k5634 & $3.1 \pm 0.4$ & $3: 2: 4: 2: 4$ & $60 a b c$ \\
\hline k5641 & $4 \pm 0.2$ & $0: 0: 6: 3: 6$ & $40 \mathrm{bcd}$ \\
\hline k5636 & $3.9 \pm 0.3$ & $0: 1: 4: 6: 4$ & $33 \mathrm{~cd}$ \\
\hline $\mathrm{k} 5639$ & $3.9 \pm 0.3$ & $0: 2: 3: 4: 6$ & $33 \mathrm{~cd}$ \\
\hline $\mathrm{k} 5640$ & $3.7 \pm 0.3$ & $2: 0: 3: 4: 6$ & $33 \mathrm{~cd}$ \\
\hline k5643 & $3.8 \pm 0.1$ & $0: 0: 3: 10: 0$ & $30 \mathrm{~d}$ \\
\hline \multicolumn{4}{|l|}{ Woondum } \\
\hline k5598 & $2.1 \pm 0.3$ & $6: 3: 4: 2: 0$ & $87 \mathrm{a}$ \\
\hline $\mathrm{k} 5602$ & $2.1 \pm 0.4$ & $8: 1: 3: 2: 1$ & $80 \mathrm{a}$ \\
\hline k5599 & $3.1 \pm 0.2$ & 1:0:9:4:0 & $71 \mathrm{ab}$ \\
\hline $\mathrm{k} 5600$ & $3.3 \pm 0.4$ & $3: 1: 3: 5: 3$ & $47 \mathrm{~b}$ \\
\hline k5601 & $3.7 \pm 0.2$ & $0: 1: 5: 5: 3$ & $43 \mathrm{~b}$ \\
\hline
\end{tabular}


ducive for disease development or if the disease becomes established in microclimates (e.g., riparian zones or high-humidity frost hollows) suited to the rust fungi. It is still unknown what the limiting factors are for P. psidii here in Australia, despite climate- and host-based models suggesting that spread and impact should mainly be restricted to subtropical and tropical coastal regions $(6,7,24)$.

The source of E. argophloia used in the study appears to affect the susceptibility of the resulting half-sib families. This is highlighted by the lower number of resistant seedlings from the Burncluith area. As indicated by Hamilton et al. (22), genetic bottlenecks and low population variation may erode genetic resistance to diseases. Little information is available about the pollination system of E. argophloia; however, because it has small buds of 0.4 by $0.4 \mathrm{~cm}$ (10), it is likely to be insect pollinated and, hence, pollen movement is likely to be over short distances (4). The Burncluith trees are isolated paddock trees in an area that has been extensively cleared for cropping. Given this, any seed produced may be more inbred and have lower variability than the other two native forest sources of E. argophloia (Burra Burri and Fairyland), which occur in intact stands of several hundred adult trees. The expected higher levels of inbreeding and lower genetic variability of the Burncluith trees may account for the lower level of resistant seedlings detected in this study.

Compared with studies on E. cloeziana susceptibility to $P$. psidii in Brazil $(1,14)$, resistance levels within provenances tested as part of this study were relatively high. This may well reflect the wide range of provenances used in this study, with results indicating that inland provenances (and ecotypes) are more resistant to $P$. psidii infection. Many of these provenances will not have been tested for $P$. psidii resistance in the previous studies, which were based on Brazilian landrace populations of unknown genetic diversity. $E$. cloeziana occurs naturally in a number of disjunct locations in Queensland, with four recognized ecotypes (36). The growing conditions across the species range vary significantly, particularly in relation to annual rainfall and evaporation, which has resulted in differences in leaf structure. Southern inland ecotypes have significantly thicker leaves (and cuticles, epidermis, and palisade layer thickness) than E. cloeziana from the southern coastal ecotype (30). Given that the mode of Puccinia infection is direct rather than via stomata, this variation in leaf structure may explain the increased levels of resistance to $P$. psidii of these inland ecotype seedlings. However, similar leaf structures were identified for $E$. argophloia and the inland ecotype of E. cloeziana (30), and the former species is highly susceptible to $P$. psidii, based on this study.

Estimates of heritability (percentage of variation attributable to genetic effects) indicate that there is a significant genetic effect controlling the level of infection in both of the species examined. Heritability was estimated for various classifications of each species based on very different geographic scales, with the broad classification of $E$. argophloia populations spread over a very narrow geographic area (20 km north to south) and the broad classification of E. cloeziana ecotypes spread over a much greater area $(1,600$ $\mathrm{km}$ north to south). Because the heritability indicates the level of genetic variance that one would expect as a proportion of the total variation within a given experimental unit, absolute changes in heritability are relevant when comparing species. In E. cloeziana, the heritability of the damage rating rose 0.08 and the heritability of the resistance score rose 0.11 when comparing the reduced and complete models classification. This is high, relative to the increases in heritability of 0.04 and 0.03 for the damage rating and resistance scores, respectively, observed in E. argophloia. This would be expected if geographic distance is related to genetic diversity, with E. cloeziana populations sourced over a much greater distance than E. argophloia populations. Furthermore, the surviving natural population of $E$. argophloia comprises approximately 1,000 mature trees whereas E. cloeziana populations are widely distributed, with some stands of cloeziana containing more individuals than the entire E. argophloia population. This extreme difference in overall population size may also contribute to the lower $h^{2}$ in general, as well as the smaller increases in genetic variance estimates when population structure effects were removed from the statistical models.

Comparing $h^{2}$ from models, including both broad and narrow genetic groupings (complete model), with those that assume no population structure was present in the populations (reduced models), provides evidence that selection of families resistant to $P$. psidii from all populations is possible. This is an important finding, because it implies that selections could be made from across the range of each species to ensure that high levels of genetic diversity are maintained within breeding populations. In addition, the longterm viability of the various populations of both species in the wild would be ensured as resistance mechanisms are widely spread among all populations. Genetic diversity within breeding populations will be important should other $P$. psidii biotypes or new diseases become established in the area where planted forests of these species will be established. This high level of within-population variation, relative to between population variation for resistance, indicates that some individuals may not successfully regenerate within native forests whereas others will successfully reproduce.

Implications for breeding programs designed to develop $P$. psidii-resistant E. argophloia and E. cloeziana stock for production plantations are (i) if a portion of the population must be culled because of $P$. psidii susceptibility, then this additional selection criteria will reduce selection intensity and, therefore, achievable gains in other economically important traits; (ii) index selection may be complicated depending on directions and degree of the genetic correlations between rust resistance and other traits; and (iii) increased variability in field trials (common garden experiments) caused by $P$. psidii infection would reduce the precision of these trials and increase competition differentials of the traditional

Table 6. Comparisons of rust resistance of families within Eucalyptus cloeziana provenances obtained from the mixed provenance seedling seed orchards

\begin{tabular}{lcccc}
\hline Provenance $^{w}$ & $\begin{array}{c}\text { Maternal } \\
\text { parent }\end{array}$ & MDR $^{\mathbf{x}}$ & $\begin{array}{c}\text { Plants/class } \\
\left(\mathbf{1 : 2 : 3 : 4 : 5 )} \mathbf{y}^{\mathbf{y}}\right.\end{array}$ & $\begin{array}{c}\text { Resistant } \\
(\mathbf{\%})^{\mathbf{z}}\end{array}$ \\
\hline Como 1 & $\times 7184$ & $3.2 \pm 0.3$ & $2: 1: 4: 8: 0$ & $47 \mathrm{a}$ \\
& $\times 7194$ & $3.6 \pm 0.3$ & $2: 0: 4: 5: 4$ & $40 \mathrm{a}$ \\
Goomborian 1 & $\times 7179$ & $3.6 \pm 0.3$ & $1: 0: 2: 7: 3$ & $23 \mathrm{a}$ \\
Helenvale 2 & $\times 7189$ & $3.6 \pm 0.7$ & $1: 0: 4: 9: 1$ & 33 \\
& $\times 6213$ & $2.9 \pm 0.3$ & $1: 3: 5: 2: 1$ & $75 \mathrm{a}$ \\
Home 1 & $\times 6219$ & $3.2 \pm 0.2$ & $0: 2: 9: 3: 1$ & $73 \mathrm{a}$ \\
& $\times 7187$ & $2.3 \pm 0.4$ & $5: 2: 4: 1: 1$ & $85 \mathrm{a}$ \\
& $\times 7188$ & $2.5 \pm 0.3$ & $1: 3: 4: 4: 0$ & $67 \mathrm{ab}$ \\
Neerdie 1 & $\times 7183$ & $3.8 \pm 0.2$ & $0: 0: 5: 8: 2$ & $33 \mathrm{bc}$ \\
Pomona 1 & $\times 7185$ & $4.1 \pm 0.3$ & $1: 0: 1: 7: 6$ & $13 \mathrm{c}$ \\
Toolara 1 & $\times 7172$ & $2.7 \pm 0.1$ & $2: 0: 6: 1: 0$ & 89 \\
& $\times 7141$ & $1.8 \pm 0.1$ & $11: 0: 1: 2: 1$ & 80 \\
Veteran 1 & $\times 7190$ & $1.8 \pm 0.3$ & $9: 2: 2: 2: 0$ & $87 \mathrm{a}$ \\
& $\times 7177$ & $3.5 \pm 0.3$ & $1: 1: 5: 5: 3$ & $50 \mathrm{~b}$ \\
Watsonville 3 & $\times 7192$ & $3.7 \pm 0.4$ & $2: 1: 4: 2: 0$ & $78 \mathrm{a}$ \\
Wolvi 1 & $\times 6210$ & $3.21 \pm 0.3$ & $3: 0: 5: 7: 0$ & $53 \mathrm{a}$ \\
& $\times 7180$ & $2.5 \pm 0.3$ & $1: 2: 4: 7: 0$ & 50 \\
& $\times 7175$ & $2.5 \pm 1.5$ & $4: 0: 7: 2: 0$ & $85 \mathrm{a}$ \\
Woondum 1 & $\times 7191$ & $3.7 \pm 0.3$ & $1: 1: 3: 5: 4$ & $50 \mathrm{ab}$ \\
& $\times 4087$ & $2.9 \pm 0.3$ & $4: 0: 4: 6: 0$ & $36 \mathrm{~b}$ \\
& $\times 7176$ & $3.1 \pm 0.3$ & $2: 3: 3: 4: 2$ & $57 \mathrm{a}$ \\
& $\times 7173$ & $3.2 \pm 0.3$ & $3: 0: 5: 5: 2$ & $53 \mathrm{ab}$ \\
& $\times 6211$ & $3.9 \pm 0.2$ & $0: 0: 4: 8: 3$ & $27 \mathrm{ab}$ \\
Yurol 1 & $\times 7193$ & $3.7 \pm 0.3$ & $2: 1: 0: 8: 4$ & $20 \mathrm{~b}$ \\
& $\times 7182$ & $2.8 \pm 0.1$ & $3: 0: 9: 1: 1$ & 86
\end{tabular}

${ }^{\mathrm{w}}$ Maternal parent provenance. Numbers after names refer to the parental ecotype: 1 = South Queensland coastal ecotype, 2 = North Queensland coastal ecotype, and $3=$ North Queensland inland ecotype.

${ }^{\mathrm{x}} \mathrm{MDR}=$ mean disease rating.

y Number of plants per severity class. Severity classes based on Junghans et al. (23), with ratings 1 to 3 being considered to be resistant.

${ }^{\mathrm{z}}$ Resistant seedling percentage followed by the same letters with the maternal parent's provenance shows means that do not differ significantly (pairwise comparison $P<0.05$ ). 
Table 7. Narrow-sense heritability estimates $\left(h^{2}\right)$ for rust resistance classified on either a 1-to-5 damage scale or a binomial scale indicating the presence of rust pustules in Eucalyptus cloeziana and E. argophloia populations

\begin{tabular}{|c|c|c|c|c|}
\hline \multirow[b]{3}{*}{ Heritability class $^{\mathbf{z}}$} & \multicolumn{4}{|c|}{$95 \% \mathbf{C I}^{\mathbf{y}}$} \\
\hline & \multicolumn{2}{|c|}{ E. cloeziana } & \multicolumn{2}{|c|}{ E. argophloia } \\
\hline & Rating (1-5) ordinal & Res/Sus (0-1) binomial & Rating (1-5) ordinal & Res/Sus (0-1) binomial \\
\hline$h^{2}$ & $0.40(0.32,0.55)$ & $0.91(0.66,1.12)$ & $0.24(0.12,0.29)$ & $0.63(0.45,0.96)$ \\
\hline$h_{\text {Broad }}^{2}$ & $0.36(0.25,0.47)$ & $0.86(0.58,1.03)$ & $0.21(0.14,0.30)$ & $0.61(0.47,0.91)$ \\
\hline$h^{2}$ Narrow & $0.31(0.21,0.45)$ & $0.73(0.57,1.05)$ & $0.21(0.12,0.27)$ & $0.72(0.44,0.96)$ \\
\hline$h^{2}$ BroadNarrow & $0.32(0.25,0.44)$ & $0.80(0.58,1.03)$ & $0.20(0.12,0.30)$ & $0.60(0.40,0.93)$ \\
\hline
\end{tabular}

y $\mathrm{CI}=$ confidence interval and Res/Sus = resistant/susceptible. $95 \%$ confidence interval = numbers in brackets under "Rating (1-5) ordinal" and "Res/Sus $(0-$ 1) binomial" columns.

z Various levels of population structure were included in the generalized linear model to account for $1=$ no population structure $\left(h^{2}\right), 2=$ broad population classification effects $\left(h^{2}\right.$ Broad $), 3=$ narrow population classification effects $\left(h^{2}{ }_{\text {Narrow }}\right)$, and $4=$ both broad and narrow population classification effects $\left(h^{2}\right.$ BroadNarrow).

seedling seed orchard genetic evaluation strategies employed for base population trials of these species (26). Nevertheless, the ability to screen in a glasshouse and identify families with variable levels of resistance and then use these ratings to target the deployment of resistant families to areas where rust is a known or potential problem provides a means of disease control. Implications of rust spreading throughout the native range for revegetation efforts include reduced stocking from rust-induced mortality, increased mortality from competing vegetation where growth is significantly retarded, as well as resultant changes in genetic variability of the species. Although this will have some impact on the development of genetically improved populations, a relatively diverse base population of both species has been assembled and resistant families may now be utilized.

The evidence presented in this study suggests that it will be possible to develop breeds of E. cloeziana and E. argophloia that have increased resistance to the biotype of $P$. psidii that has become established in Australia. The results of these analyses will be used to identify different deployment populations for both species; one with a high level of rust resistance for use in plantation areas where $P$. psidii is a known problem and another with greater emphasis placed on economically important traits for use in areas where the rust is not expected to be an issue. There is also a need to determine whether the resistance to the single rust biotype identified in Australia confers resistance to different biotypes present in other countries, particularly Brazil, where multiple biotypes are known. In addition to this, testing of isolates of $P$. psidii collected from a range of hosts and locations over time in Australia will be important, accompanied by development of a host differential suite, to allow for rapid testing for differences in isolate aggressiveness between different isolates or changes in the pathogen over time. Considering the global significance of eucalypts as sources of wood and fiber, an international collaborative approach to managing this significant disease is crucial.

\section{Acknowledgments}

We thank J. Oostenbrink, J. Huth, and T. Burridge for preparation of seedlings and D. Osborne for review and critical comments for this manuscript. This research was funded by the Queensland Government via the Department of Agriculture, Fisheries and Forestry.

\section{Literature Cited}

1. Alfenas, R. F., Coutinho, M. M., Freitas, C. S., Freitas, R. G., and Alfenas, A. C. 2012. Developing clones of Eucalyptus cloeziana resistant to rust (Puccinia psidii). In: Proc. 4th Int. Workshop Genet. Host-Parasite Interactions in Forestry: Disease and Insect Resistance in Forest Trees. R. A. Sniezko, A. D. Yanchuk, J. T. Kliejunas, K. M. Palmieri, J. M. Alexander, and S. J. Frankel, tech. coord.

2. Atlas of Living Australia. http://www.ala.org.au/

3. Baker, A., and Walker, S. 2005. Assessment of the relative amenability to vegetative propagation by leafy cuttings of 14 tropical and subtropical $E u$ calyptus and Corymbia species. Pages 79-88 in: Plantation Technology in Tropical Forest Science. K. Suzuki, K. Ishii, S. Sakurai, and S. Sasaki, eds. Springer-Verlag, Tokyo.

4. Barbour, R. C., Potts, B. M., and Vaillancourt, R. E. 2005. Pollen dispersal from exotic eucalypt plantations. Conserv. Genet. 6:253-257.

5. Boland, D. J., Brooker, M. I. H., Chippendale, G. M., Hall, N., Hyland, B.
P. M., Johnson, R. D., Kleinig, D. A., McDonald, M. W., and Turner, J. D. 2006. Forest Trees of Australia, 5th ed. CSIRO Publishing, Melbourne, Australia.

6. Booth, T. H., and Jovanovic, T. 2012. Assessing vulnerable areas for Puccinia psidii (eucalyptus rust) in Australia. Australas. Plant Pathol. 41:425429.

7. Booth, T. H., Old, K. M., and Jovanovic, T. 2000. A preliminary assessment of high risk areas for Puccinia psidii (Eucalyptus rust) in the Neotropics and Australia. Agric. Ecosyst. Environ. 82:295-301.

8. Brawner, J. T., Lee, D. J., Hardner, C. M., and Dieters, M. J. 2011. Relationships between early growth and Quambalaria shoot blight tolerance in Corymbia citriodora progeny trials established in Queensland, Australia. Tree Genet. Genomes 7:759-772.

9. Brawner, J. T., Meder, R., Dieters, M., and Lee, D. J. 2012. Selection of Corymbia citriodora for pulp productivity. South. For. 74:121-131.

10. Brooker, M. I. H., and Kleinig, D. A. 2004. Field Guide to Eucalypts; Volume 3, Northern Australia. Bookbuilders Ltd., Melbourne, Australia.

11. Carnegie, A. J., and Lidbetter, J. R. 2012. Rapidly expanding host range for Puccinia psidii sensu lato in Australia. Australas. Plant Pathol. 41:13-29.

12. Carnegie, A. J., Lidbetter, J. R., Walker, J., Horwood, M. A., Tesoriero, L., Glen, M., and Priest, M. J. 2010. Uredo rangelii, a taxon in the guava rust complex, newly recorded on Myrtaceae in Australia. Australas. Plant Pathol. 39:463-466.

13. Coutinho, T. A., Wingfield, M. J., Alfenas, A. C., and Crous, P. W. 1998. Eucalyptus rust: A disease with the potential for serious international implications. Plant Dis. 82:819-825.

14. Dianese, J. C., Moraes, T. S., and Silva, A. R. 1984. Response of Eucalyptus species to field infection by Puccinia psidii. Plant Dis. 68:314-316.

15. Falconer, D. S., and Mackay, T. F. C. 1996. Introduction to Quantitative Genetics. Addison Wesley Longman Limited, Harlow, Essex, UK.

16. Gilmour, A. R., Anderson, R. D., and Rae, A. L. 1985. The analysis of binomial data by a generalized linear mixed model. Biometrika 72:593-599.

17. Gilmour, A. R., Gogel, B. J., Cullis B. R., and Thompson, R. 2009. ASReml User Guide Release 3.0. VSN International Ltd., Hemel Hempstead, UK.

18. Glen, M., Alfenas, A. C., Zauza, E. A. V., Wingfield, M. J., and Mohammed, C. 2007. Puccinia psidii: A threat to the Australian environment and economy a review. Australas. Plant Pathol. 36:1-16.

19. Griffin, A. R., and Cotterill, P. P. 1988. Genetic variation in growth of outcrossed, selfed and open-pollinated progenies of Eucalyptus regnans and some implications for breeding strategy. Silv. Genet. 37:124-131.

20. Hadfield, J. D. 2010. MCMC methods for multi-response generalized linear mixed models: The MCMCglmm R Package. J. Stat. Softw. 33:1-22.

21. Hadfield, J. D., and Nakagawa, S. 2010. General quantitative genetic methods for comparative biology: Phylogenies, taxonomies and multi-trait models for continuous and categorical characters. J. Evol. Biol. 23:494-508.

22. Hamilton, M. G., Willaims, D. R., Tilyard, P. A., Pinkard, E. A., Wardlaw, T. J., Glan, M., Vaillancourt, R. E., \& Potts, B. M. 2013. A latitudinal cline in disease resistance of a host tree. Heredity 110:372-379.

23. Junghans, D. T., Alfenas, A. C., and Maffia, L. A., 2003. Escala de notas para quantificao da ferrugem em Eucalyptus. Fitopatol. Bras. 28:184-188.

24. Kriticos, D. J., Morin, L., Leriche, A., Anderson R. C., and Caley P. 2013. Combining a climatic niche model of an invasive fungus with its host species distributions to identify risks to natural assets: Puccinia psidii sensu lato in Australia. PLoS One 8:e64479.

25. Lee, D. J. 2007. Achievements in forest tree improvement in Australia and New Zealand 2: Development of Corymbia species and hybrids for plantations in eastern Australia. Aust. For. 70:11-16.

26. Lee, D. J., Nikles, D. G., and Walker, S. M. 1999. Strategy and progress on the genetic improvement of hardwood timber species in Queensland. Pages 38-40 in: Proc. 11th Aust. Plant Breed. Conf. Vol. 2. P. Langridge, A. Barr, G. Auricht, G. Collins, A. Granger, D. Handford, and J. Paull, eds. CRC for Molecular Plant Breeding, Adelaide, Australia.

27. Lee, D. J., Zbonak, A., and McGavin, R. 2011. Development of E. argophloia in Queensland: Lessons learnt. Pages 55-66 in: Developing a Eu- 
calypt Resource: Learning from Australia and Elsewhere. J. Walker ed. University of Canterbury, Blenhein, New Zealand.

28. Morin, L., Aveyard, R., Lidbetter, J. R., and Wilson, P. G. 2012. Investigating the host-range of the rust fungus Puccinia psidii sensu lato across tribes of the family Myrtaceae present in Australia. PLoS One 7:e35434.

29. Nature Conservation (Wildlife) Regulation. 2006. Queensland, Australia.

30. Ngugi, M. R., Doley, D., Hunt, M. A., Dart, P., and Ryan, P. 2003. Leaf water relations of Eucalyptus cloeziana and Eucalyptus argophloia in response to water deficit. Tree Physiol. 23:335-343.

31. Pegg, G. S., Brawner, J. T., and Lee, D. J. 2014. Screening Corymbia populations for resistance to Puccinia psidii. Plant Pathol. 63:425-436.

32. Pegg, G. S., Giblin, F. R., McTaggart, A. R., Guymer, G. P., Talyor, H., Ireland, K. B., Shivas, R. G., and Perry, S. 2014. Puccinia psidii in Queensland, Australia: Disease symptoms, distribution and impact. Plant Pathol. 63:1005-1021. doi:10.1111/ppa.12173

33. Roux, J,, Greyling, I., Coutinho T. A., Verleur, M., and Wingfield, M. J. 2013. The Myrtle rust pathogen, Puccinia psidii, discovered in South Afri- ca. IMAFungus 4:155-159.

34. Stokoe, R. L., Shepherd, M., Lee, D. J., Nikles, D. G., and Henry, R. J. 2001. Natural Inter-subgeneric hybridization between Eucalyptus acmenoides Schauer and Eucalyptus cloeziana F. Muell (Myrtaceae) in Southeast Queensland. Ann. Bot. 88:563-570.

35. Trueman, S. J., McMahon, T. V., and Bristow, M. 2013. Production of Eucalyptus cloeziana cuttings in response to stock plant temperature. J. Trop. For. Sci. 25:60-69.

36. Turnbull, J. W. 1983.Provenance variation in Eucalyptus cloeziana F. Muell. Pages 508-511 in: Simposio IUFRO Em melhoramento genetico E produtividade de especies florestais de rapido crescimento, Vol. 31. ANAIS, Sao Paulo, Brazil.

37. Uchida, J., Zhong, S., and Killgore, E. 2006. First report of a rust disease on 'Ohi' a caused by Puccinia psidii in Hawaii. Plant Dis. 90:524.

38. Zauza, E. A. V., Alfenas, A. C., Old, K., Couto, M. M. F., Graca, R. N., and Maffia, L. A. 2010. Myrtaceae species resistance to rust caused by Puccinia psidii. Australas. Plant Pathol. 39:406-411. 